\title{
ICTERUS NEONATORUM
}

\section{The Rôle of the Placenta in Visible Icterus Neonatorum}

\author{
By R. GOTTLIEB AND P. J. KEARNS
}

(From the Department of Medicine, McGill University Clinic, and the Royal Victoria Maternity Hospital, Montreal)

(Received for publication January 24, 1931)

In three previous publications on icterus neonatorum one of us (1) has demonstrated that the polycythaemia in the new-born is due probably to an anoxaemia of the foetus in utero and is an expression of compensation by the active haematopoietic system. After birth the excess of red blood corpuscles is rapidly destroyed, since they are no longer required for the maintenance of oxygenation. The rapid blood destruction leads to an increase of the bilirubin in the serum and jaundice.

We concluded that "icterus neonatorum is a physiological condition, which is the result of a postnatal readjustment from an environment requiring the presence of polycythaemia for the maintenance of oxygenation to one in which no such extraordinary measures are necessary. Icterus is present in all infants, visibility being only a matter of degree."

Although we contend that visible jaundice is but the final result of the conditions existing in the new-born infant, it may be that there are certain other factors which in some cases will make visible jaundice a more prominent feature.

The natural weakness of the placenta as a respiratory organ, in comparison with the lung, and its tendency to marked degenerative changes, suggested to us a possible source for an intensification of the degree of foetal anoxaemia, polycythaemia and resultant icterus.

We therefore studied the relation of the condition of the placenta to the degree of jaundice in 85 consecutive new-born infants.

The method of procedure was as follows: As soon as the infant was born and before delivery of the placenta a sample of umbilical blood was taken. A complete morphological study of the erythrocytes was 
made and the bilirubin content was estimated by the Van den Bergh reaction. These studies were repeated daily in the infant for one week and the appearance of visible jaundice was watched for carefully. Sections of the placenta were taken in each case and thoroughly studied.

The degree of jaundice as well as the changes in the placenta were classified in three groups: mild, moderate and severe.

TABLE 1

Showing number of subjects in each group

\begin{tabular}{|c|c|c|c|c|c|}
\hline & \multicolumn{5}{|c|}{ Placental changes } \\
\hline & None & Mild & Moderate & Severe & Total \\
\hline Jaundice not visible $\ldots \ldots \ldots \ldots$. & 31 & 9 & 0 & 0 & 40 \\
\hline Jaundice visible......... & 14 & 9 & 12 & 10 & 45 \\
\hline Total.......... & 45 & 18 & 12 & 10 & 85 \\
\hline
\end{tabular}

TABLE 2

Relation of polycythaemia and bilirubinaemia at birth to the condition of the placenta in 85 cases

\begin{tabular}{|c|c|c|c|c|}
\hline & \multicolumn{4}{|c|}{ Placental changes } \\
\hline & None & Mild & Moderate & Severe \\
\hline \multicolumn{5}{|l|}{ Jaundice not visible: } \\
\hline Red blood cells, millions... & 5.21 & 5.25 & & \\
\hline Hemoglobin, per cent........... & 102 & 102 & & \\
\hline Van den Bergh units........ & 2.8 & 2.8 & & \\
\hline \multicolumn{5}{|l|}{ Jaundice visible: } \\
\hline Red blood cells, millions.............. & 6.20 & 5.90 & 6.55 & 7.11 \\
\hline Hemoglobin, per cent.............. & 116 & 110 & 118 & 122 \\
\hline Van den Bergh units................ & 5.5 & 4.2 & 5.7 & 6.8 \\
\hline
\end{tabular}

Placentae classified as "mild degenerative changes" showed no macroscopic pathology. Microscopic sections showed numerous partly or completely hyalinized villi affording evidence of advancing senile change in the vascular tree. Those classified as "moderate degenerative changes" showed macroscopically whitish infarcted areas or scattered soft sequestra of tissue and microscopically either large 
hyalinized areas of villi, sometimes with productive changes in the chorionic membrane, or irregular areas of intervillous congestion, evidence of early maternal infarction. Those described as "severe degenerative changes" showed macroscopically relatively thick, greyish friable placentae with large whitish or infarcted areas or large soft sequestra as evidence of maternal infarction. Microscopic examination substantiated this.

In 40 out of the 85 cases studied, changes in the placenta were found. In 31 of these 40 cases visible jaundice was present, that is in 78 per cent of these cases with changes in the placenta, while 9 cases or 22 per cent did not show any visible jaundice. The changes of the placenta in these 9 cases were, however, all in the group of "mild changes."

In 45 of the 85 cases, visible jaundice was present; 31 of them had changes in the placenta, that is 69 per cent of all the cases exhibiting visible jaundice, while 14 cases or 31 per cent did not show any placental changes.

Table 1 shows the relation of jaundice to the condition of the placenta.

The relation of the polycythaemia and bilirubinaemia is demonstrated in table 2.

From this table one can see that changes of the placenta would appear to lead to an increase in the foetal polycythaemia as well as the foetal bilirubinaemia. That is especially the case where the placental changes are well marked, as in the group of the moderate and severe changes.

\section{DISCUSSION OF FINDINGS}

From the above findings it can be seen that changes of the placenta, if marked enough, lead to an exaggeration of the prenatal conditions, that is an increase in the foetal polycythaemia and bilirubinaemia or, in other words, marked changes of the placenta diminish its respiratory ability, intensifying the already existing foetal anoxaemia, which in turn calls forth for an increase in the compensatory polycythaemia. In the process of adaptation to postnatal conditions in these cases it is quite obvious that the greater amount of red blood corpuscles offered for destruction will cause a deepening of the postnatal increase of the bilirubinaemia and eventually lead to visibility of the jaundice. 
The 14 cases of visible jaundice without changes in the placenta, on the other hand, show that placental changes, although an important factor in intensifying the degree of icterus neonatorum, are not responsible on every case. Other factors as yet unknown may come into play.

\section{CONCLUSION}

Pathological changes in the placenta are associated with an increase in the foetal polycythaemia, with a subsequent increase in the degree of icterus neonatorum, making its visibility a more marked feature.

\section{BIBLIOGRAPHY}

(1) Goldbloom, A., and Gottlieb, R., Am. J. Dis. Child., 1929, xxxviii, 57. Icterus Neonatorum.

Goldbloom, A., and Gottlieb, R., J. Clin. Invest., 1930, viii, 375. Studies on Icterus Neonatorum. The Production of Icterus in Animals Following Prolonged Anoxaemia.

Goldbloom, A., and Gottlieb, R., J. Clin. Invest., 1930, ix, 139. Icterus Neonatorum. III. The Oxygen Capacity and Saturation of the Mother and Foetus. 